\author{
ARGONNE NATIONAL LABORATORY \\ P. O. Box 299 \\ Lemont, Illinois
}

\title{
A STUDY OF MECHANICAL-ELECTROLYTIC POLISHING ON URANIUM METALIOGRAPHIC SPECIMENS
}

\author{
by \\ Floyd L. Brown \\ January, 1957 \\ Metallurgy Division \\ Program 6.1.3
}

This report supersedes sections of the following Metallurgy Division Quarterly Progress Reports:
ANL -4399
pp. $92-93,96$
December 31, 1949
ANL-4507 pp. 46-47
March 31, 1950

Operated by The University of Chicago

under

Contract $W-31-109-$ eng-38 


\section{DISCLAIMER}

This report was prepared as an account of work sponsored by an agency of the United States Government. Neither the United States Government nor any agency Thereof, nor any of their employees, makes any warranty, express or implied, or assumes any legal liability or responsibility for the accuracy, completeness, or usefulness of any information, apparatus, product, or process disclosed, or represents that its use would not infringe privately owned rights. Reference herein to any specific commercial product, process, or service by trade name, trademark, manufacturer, or otherwise does not necessarily constitute or imply its endorsement, recommendation, or favoring by the United States Government or any agency thereof. The views and opinions of authors expressed herein do not necessarily state or reflect those of the United States Government or any agency thereof. 


\section{DISCLAIMER}

Portions of this document may be illegible in electronic image products. Images are produced from the best available original document. 


\section{2}

\section{TABLE OF CONTENTS}

Page

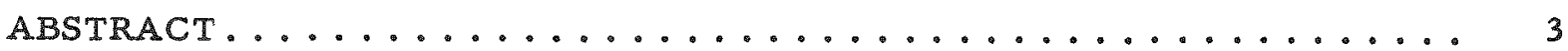

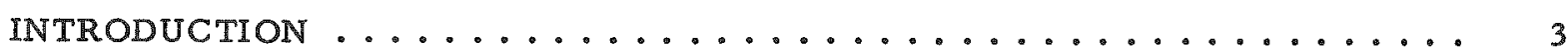

EXPERIMENTAL PROCEDURES .................... 4

Specimen Cutting and Mounting.................... 4

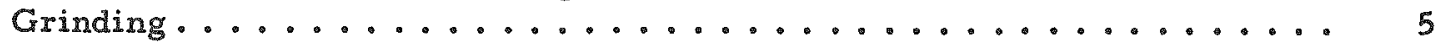

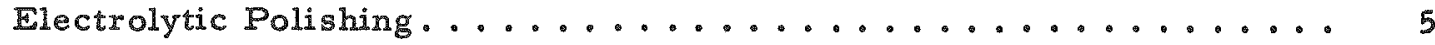

EVALUATION OF RESULTS ......................

Contamination in Cutting ...................... 6

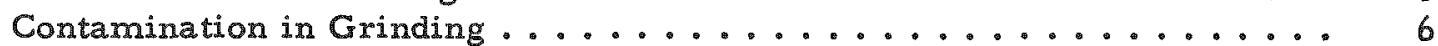

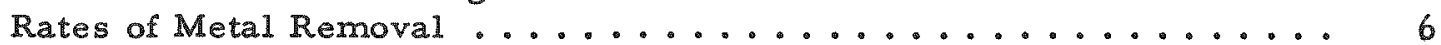

Current Requirements for Electropolishing ............... 7

Depth of Scratches and Cold Worked Layers ................ T

Choosing an Optimum Procedure ................... 7

\section{LIST OF TABLES}

No.

Title

I. Contamination of Surroundings by Hand Grinding ..............

II. Metal Removal Rates for Mechanical Grinding and Electrolytic Polishing.

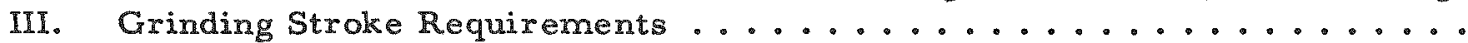

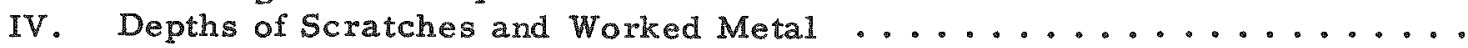

V. Metal Removal Rates for Different Grinding Procedures...........

\section{LIST OF FIGURES}

No.

1. Procedure for Molding Electrical Contact into Bakelite Mount . . . . . . .

2. Electropolishing Curves for Normal Uranium, Back-Connected in

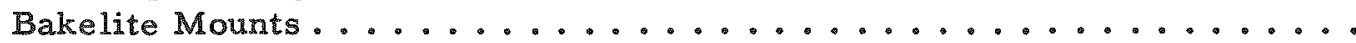

3. Depth of Scratches and Cold Worked Layers ............... 14

4. Micros of Specimens Saw Cut and Electropolished ............. 15

5. Micros of Specimens Saw Cut, Polished on Grade 2 Emery Paper, and

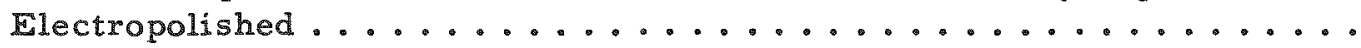

6. Micros of Specimens Saw Cut, Polished on Grades 2 and $2 / 0$ Emery Polishing Paper, and Electropolished ..................

7. Micros of Specimens Saw Cut, Polished on Grades 2, 2/0, and 3/0 Emery Polishing Papers, and Electropolished...............

8. Micros of Specimens Saw Cut, Polished on Grades 2, 2/0,3/0, and $4 / 0$ Emery Polishing Papers and Electropolished ............. 


\begin{abstract}
$\rightarrow$
A STUDY OF MECHANICAL-ELECTROLYTIC POLISHING ON URANIUM METALLOGRAPHIC SPECIMENS
\end{abstract}

Floyd L. Brown

\begin{abstract}
Proposed techniques for "hot" metallographic preparation are described. The following data from experiments on saw cutting, hand grinding, and electrolytic polishing have been obtained:
\end{abstract}

1. Radioactive contamination from saw cutting and grinding.

2. Depths of scratches and cold worked metal from saw cutting and grinding.

3. Metal removal rates for various grades of emery grinding papers.

4. Metal removal rates for electropolishing.

5. Optimum sequence for specimen grinding on emery papers.

6. Time requirements for satisfactory electrolytic polishing of saw cut, rough ground, and fine ground uranium specimens.

It has been shown that an efficient and effective procedure for preparation of saw cut uranium is the removal of about three-fourths of the cold worked layer with grade number 2 paper, followed by grades $3 / 0$ and $4 / 0$. The remaining fine scratches and thin layer of cold worked metal were removed by prolonged electropolishing in phosphoric acid-ethylene glycol-ethyl alcohol solution.

\title{
INT RODUCTION
}

Early work directed toward the development of techniques for "hot" metallography were based on the premise that the problem of radioactive contamination was extremely formidable. Later developments weakened this premise and therefore many procedures originally proposed were not adopted. However, information gained in the development of these procedures provided helpful information for evaluation of grinding techniques and data pertinent to metallographic preparation in general. 
For example, it was assumed that mechanical operations would be required at slow speeds to prevent contaminating spatter, as from an abrasive cutoff wheel or a rotating lap. Therefore, in early tests, saw cutting and slow hand grinding were proposed to replace cutoff and lapping, respectively. Electrolytic polishing was considered for final polishing as being a simpler and more practical method of overcomins, spatter than some slow me chanical method.

Studies outlined in this report, and based on the above assumptions, were made on unirradiated normal uranium specimens to give some insight into those proposed procedures.

\section{EXPERIMENTAI PROCEDURES}

Specimens of normal uranium were prepared by saw cutting and subsequent grinuing on various grades of emery papers. These specimens, having various surface finishes, were then electropolished to provide data on the time and current required to produce satisfactory microstructures.

Other saw cut specimens were ground, as above, to determine metal removal rates and to arrive at an optimum sequence of emery papers for grinding. Grinding scratch lepth and cold work depth were determined by electrolytic methods.

Analyses of aix samples for radioactivity were made to evaluate severity of the attendant contamination.

Specimen Cutting and Mounting

A natural uranium slug, 1-3/16" in diameter by 4 "long, was used for the tests. Prior treatment was unknown, but the slug had a fairly uniform, small grain size, which was considered suitable for the study.

The slug was sectioned on a milling machine while air samples were taken in the immediate vicinity. Use of coolant was eliminated to provide worst possible conditions of contamination. Three longitudinal and three transverse cuts were made in such a manner as to yield small bars with saw cut surfaces for subsequent polishing experiments. Arbor and table speeds were set as slow as possible. Feed rate was varied, and both side cutter and slitting saws were tried.

To provide specimens of uniform size, the sectioned bars were further cut into $1 / 4^{\prime \prime}$ cubes. For these final cuts an abrasive cutoff wheel was used because of the lack of a suitable clamping device for saw cutting the smaller sizes. One sav cut surface on each cube was left undisturbed for the grinding and polishing tests. The cubes were mounted in bakelite with an electrical contact through the back of the mount. Conventional mounting equipment was used, and the method of incorporating the contact is shown in Figure 1 . 
Grinding

Considerable effort was expended in acquiring uniformity of speed and pressure during hand grinding. Speed was easily regulated by timing the strokes. Pressure of specimen against emery paper was more difficult to judge and was left to sense of feel of the operator.

Air-borne contamination from grinding operations was detected by radiation monitoring of air samples continuously collected near the abrasive papers.

Extended grinding was done on fine and coarse papers, at slow and fast speeds, with and without lubrication, and with single and with overlapping strokes, to check on amounts of contamination contributed by each variable.

Rates of metal removal were determined by weight lost by a mounted $1 / 4^{\prime \prime} \times 1 / 4^{\prime \prime}$ specimen after grinding.

Tests were also made to establish an optimum sequence for using emery papers. This was done by grinding $1 / 4^{\prime \prime} \times 1 / 4^{\prime \prime}$ mounted specimens and counting the number of strokes required on each grade of paper to remove scratches made by each preceding coarser grade. Six grades of paper were tested dry and two with lubrication. All tests were made at two speeds. Two of the "as cut" specimens were electrolytically polished, as later described. Twelve mounted specimens were ground using a series of emery papers. Grinding was discontinued on two specimens after each succeeding grade of paper, so that all stages of the sequence were represented in duplicate from dry grinding. Grades $3 / 0$ and $4 / 0$ were represented also from wet grinding (kerosene-paraffin). After each five hours of electropolishing, specimens were removed and photomicrographs made.

Electrolytic Polishing

Normally, specimens are polished in an electrolytic bath using a platinum touch wire. This method is unattractive for "hot" operation because of the pitting which occurs at the contact point and which obliterates a considerable portion of the surface, particularly during extended polishing times. For this reason the specimens were connected through the backs of the mounts, as described previously. Also, current requirements could be greatly reduced because of the insulated lead wire in the bakelite. Tests were made to determine current requirements for polishing.

The conventional phosphoric acid electrolyte was used ( 5 parts ethylene glycol, 8 parts ethyl alcohol, and 5 parts orthophosphoric acid). Only $100 \mathrm{ml}$ of electrolyte was used to reduce handling and storing problems which would be encountered in "hot" operation. 
Metal removal rate of polishing was determined by measurements of weight and thickness before and after long exposures.

The electrolytic method was also used to determine depths of cutting and grinding scratches. Specimens with various surface finishes including "as cut," were electropolished until the striations or scratches were invisible to the unaided eye. The depth was determined from polishing time and metal removal rate. Further polishing of the same specimen until all worked metal was removed provided a depth measurement of material cold worked by cutting and by each grade of grinding.

\section{EVALUATION OF RESULTS}

\section{Contamination in Cutting}

Considerable sparking occurred during saw cutting tests, especially during initial cuts when side cutters and more rapid speeds and feeds were used. However, aix sample analyses disclosed no evidence to indicate contamination of the air or surroundings. Satisfactory cutting conditions were as follows:

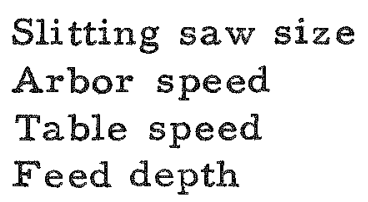

Slitting saw size

Arbor speed

Feed depth

$$
\begin{gathered}
4^{\prime \prime} \times 1 / 16^{\prime \prime} \\
17 \mathrm{rpm} \\
3 / 4^{\prime \prime} \text { perminute } \\
1 / 8^{\prime \prime}
\end{gathered}
$$

Contamination in Grinding

Analyses of air samples taken during hand grinding tests disclosed that surroundings were contaminated when dry papers and overlapping strokes were used. Contamination was not indicated, however, when papers were lubricated with kerosene-paraffin solution or when any given area of the dry paper was restricted to one stroke of the specimen. Results are given in Table $I$.

Rates of Metal Removal

By Grinding. Table II lists the results of tests to determine metal removal rates of emery grinding papers. It may be noted that metal removal rates decrease rapidly with succeeding grades of papers, except for intermediate papers, grades $1 / 0$ and $2 / 0$. These grades have nearly identical removal rates, indicating the possibility of economies in the grinding procedure by elimination of the $1 / 0$ paper from the grinding sequence. Comparison of the metal removal rates shows that the coaxse No. 2 paper is far superior to the finer grades, and that the finest paper, grade No. $4 / 0$, is far superior to electrolytic polishing. 
- The number of strokes necessary of each paper grade for removal of scratches from coarser grades is shown in Tables IIla and IIrb.

By Polishing. The metal removal rate for electrolytic polishing was found to be approximately $0.13 \mathrm{mils}$ per hour (Table II) for a back-connected uranium specimen. One hundred $\mathrm{ml}$ of phosphoric acid electrolyte was capable of polishing a $1 / 4^{\prime \prime} \times 1 / 4^{\text {" }}$ surface of uranium for about 20 hours without excessive pitting.

Current Requirements for Electropolishing

Figure 2 illustrates curves of current vs. voltage for five different specimens and indicates that correct conditions for polishing $1 / 4^{\prime \prime} \times 1 / 4^{\prime \prime}$ back-connected specimens is about 10 volts and 2 to 6 milliamperes per square centimeter.

Depth of Scratches and Cold Worked Layers

The values for the depths of scratches and of worked metal for several grades of papers (calculated from electrolytic polishing tests using the electrolytic removal rate of $0.13 \mathrm{mils}$ per hour) are listed in Table IV and illustrated graphically in Figure 3. The method for determining scratch depths admittedly did not give true values because electrolytic polishing action does not remove metal just from promontories; a fraction of the electrolytic attack occurs in the bottoms of the scratches and hence the depth determined is slightly in excess of the true scratch depth.

These data permit calculation of metal removal rates for emery papers used in sequence. Scratch depth for each paper (Table IV) divided by the average number of strokes required for removal on the succeeding paper (Table III) gives the removal rates as listed in Table V. It may be noted that grinding in sequence gives removal rates that are higher than those previously determined (by prolonged grinding) by a factor of about 3. This is to be expected because the earlier tests did not take into consideration the effect of the prior surface. The faster removal rates are valid only during the time required to grind away the previous scratches; when previous scratches are removed, the rate drops to the lower value.

Choosing an Optimum Procedure

The Grinding Sequence. Results of tests to determine an optimum sequence for grinding are listed in Table IIIa. A summary of the tests, the average number of strokes required for any sequence, is given in Table IIIb. It was found that slow stroking removed scratches from preceding papers more quickly than rapid stroking, probably due to the decreased tendency to rock which resulted in rounding of the surface of the specimen. Therefore, data are listed only for the more practical, slow 
stroking tests. All sequences started with grade No. 2 paper and ended with grade No. $4 / 0$ paper; thus, variations were due to the scheduling of the four intervening grades, Nos. $1,1 / 0,2 / 0$, and 3/0. Sequences which required the least amount of grinding were as follows:

1. 84 strokes (average), 4 papers: $2,2 / 0,3 / 0,4 / 0$

2. 85 strokes (average), 4 papers: $2,1 / 0,3 / 0,4 / 0$

3. 86 strokes (average), 4 papers: $2,1,3 / 0,4 / 0$

4. 87 strokes (average), 3 papers: $2,3 / 0,4 / 0$

5. 95 strokes (average), 5 papers: $2,1,2 / 0,3 / 0,4 / 0$

The first sequence was optimum from the standpoint of the number of grinding strokes required. However, the fourth sequence was selected as the optimum sequence because one additional grinding step was eliminated at a cost of only three more grinding strokes. Thus, the optimum sequence for preparation on emery papers called for intermediate grinding only on grade No. $3 / 0$ paper.

Electrolytic polishing of specimens representing stages of preparation from saw cutting to grinding on $4 / 0$ paper progressed through three phases: first, the uneven surface was leveled; then the work hardened metal left by saw cutting was polished away; and finally, the unaffected uranium metal was polished. Photomicrographs taken at 5-hour intervals are shown in Figures 4 through 8 . Micros illustrating specimens prepared by wet polishing with kerosene-paraffin lubricant are not included as there was no apparent difference from those prepared dry.

Electropolishing Speed. About 70 hours were required to reveal the work-free microstructures of the saw cut specimens. A minimum amount of grinding on grade No. 2 emery paper reduced the electrolytic polishing time to 50 houxs; however, additional grinding on finer grades of papers did not further reduce the polishing time by an appreciable amount. It was concluded that the time involved in the electrolytic polishing operation was dependent upon the depth of cold worked metal left by the saw cutting operation and that the coarse grade of grinding paper was the one most effective in the removal of this layer of worked metal. Calculations using electrolytic metal removal rates showed that the cold worked metal from saw cutting penetrated to depths of 7 to 9 mils.

Figure 3 illustrates the optimum procedure for preparation of saw cut specimens: about $3 / 4$ of the cold worked metal is rapidly removed by grinding on grade No. 2 emery paper, then the optimum sequence of $3 / 0$ and $4 / 0$ paper is followed, and finally, the specimen is electropolished. The time of all operations requires less than 2 hours. 
Table I

CONTAMINATION OF SURROUNDINGS BY HAND GRINDING ON BEHR-MANNING EMERY POLISHING PAPER

\begin{tabular}{|l|c|c|c|}
\hline & $\begin{array}{c}\text { Test No. 1 } \\
\text { (Overlapping } \\
\text { Strokes) }\end{array}$ & $\begin{array}{c}\text { Test No. 2 } \\
\text { (No Overlapping } \\
\text { Strokes) }\end{array}$ & $\begin{array}{c}\text { Test No. 3 } \\
\text { (Overlapping } \\
\text { Strokes) }\end{array}$ \\
\hline $\begin{array}{l}\text { Polishing paper grade No.* } \\
\text { Lubricant }\end{array}$ & $\begin{array}{c}2 \text { and 3/0 } \\
\text { Strokes per minute }\end{array}$ & 2 and 3/0 & 2 and 3/0 \\
Strokes per 9" $\times 14^{\prime \prime}$ paper & 250 & 75 to 85 & K-P** \\
Air sample analysis & Contaminated & Not contaminated & Not contaminated \\
\hline
\end{tabular}

*Polishing time: $1 / 2$ hour for each test.

**Kerosene-paraffin solution in the proportion of 50 grams of paraffin per liter of kerosene.

Table II

METAL REMOVAL RATES FOR MECHANICAL GRINDING AND ELECTROLYTIC POLISHING*

\begin{tabular}{|cc|c|c|c|}
\hline & Mils/hour & Minutes/mil & Mils/stroke \\
\hline Grade of Emery Polishing Paper & 2 & 119.5 & 0.5 & 0.0362 \\
& 1 & 81.0 & 0.7 & 0.0154 \\
$1 / 0$ & 49.0 & 1.2 & 0.0080 \\
$2 / 0$ & 24.5 & 2.5 & 0.0074 \\
$3 / 0$ & 11.0 & 5.5 & 0.0033 \\
& $4 / 0$ & 3.6 & 16.5 & 0.0011 \\
\hline Electrolytic Polishing & & 0.13 & 460.0 & - \\
\hline
\end{tabular}

* Mechanical grinding on Behr-Manning Emery Polishing Papers, 600 strokes on each paper, 50 to 60 strokes per minute. Electrolytic polishing of back-connected normal uranium in phosphoric-glycol electrolyte. 
Table III

\section{GRINDING STROKE REQUIREMENTS}

IIIa. Number of strokes required on each grade of BehrManning Emery Polishing Paper to remove scratches from each preceding grade. Not more than 20 strokes on one 9" $x 14$ " paper. Data for wet or dry grinding, 50 to 60 strokes per minute.

\begin{tabular}{|c|c|c|c|c|c|}
\hline $\begin{array}{c}\text { Emery Polishing } \\
\text { Paper Grade No. }\end{array}$ & \multicolumn{5}{|c|}{ Grade of Scratches Removed } \\
\hline 1 & $13-18$ & & 1 & $2 / 0$ & $3 / 0$ \\
\hline $1 / 0$ & $14-28$ & $12-20$ & & & \\
$2 / 0$ & $15-25$ & $10-22$ & $10-16$ & & \\
$3 / 0$ & $34-50$ & $21-32$ & $14-24$ & $16-22$ & \\
$4 / 0$ & & & & $65-100$ & $35-56$ \\
\hline
\end{tabular}

IIIb. Average number of strokes required for any sequence of Behr-Manning Emery Polishing Papers, 50 to 60 strokes per minute, wet or dry grinding.

\begin{tabular}{|c|c|c|c|}
\hline Fine Grades & $\begin{array}{l}2 / 0 \\
3 / 0\end{array}$ & $2 / 0$ & $3 / 0$ \\
$4 / 0$ & $4 / 0$ & $4 / 0$ \\
\hline $2,1,1 / 0$ & 108 & 131 & 95 \\
$2,1 / 0$ & 121.1 & 85 \\
2,1 & 118 & 86 \\
2 & 85 & 107 & 87 \\
\hline
\end{tabular}


Table IV

DEPTHS OF SCRATCHES AND WORKED METAL FROM GRINDING PAPERS USED IN SEQUENCE

\begin{tabular}{|c|c|c|}
\hline Surface Preparation & $\begin{array}{c}\text { Depth of Scratches } \\
\text { (mils) }\end{array}$ & $\begin{array}{c}\text { Depth of Worked Metal } \\
\text { (mils) }\end{array}$ \\
\hline Saw cut & 1.3 & 8.0 \\
Emery Paper No. 2 & 0.5 & 0.6 \\
Emery Paper No.2/0 & 0.2 & 0.3 \\
Emery Paper No.3/0 & 0.15 & 0.25 \\
Emery Paper No.4/0 & 0.10 & 0.20 \\
\hline
\end{tabular}

Table V

METAL REMOVAL RATES FOR DIFFERENT GRINDING PROCEDURES

\begin{tabular}{|c|c|c|}
\hline $\begin{array}{c}\text { Grade of Behr-Manning } \\
\text { Emery Polishing Paper }\end{array}$ & \multicolumn{2}{|c|}{ Metal Removal Rates (mils/stroke) } \\
\cline { 2 - 3 } 2 & 0.0362 & - \\
$2 / 0$ & 0.0074 & 0.0250 \\
$3 / 0$ & 0.0033 & 0.0105 \\
$4 / 0$ & 0.0011 & 0.0033 \\
\hline
\end{tabular}

(a) Data from Table II.

(b) Adapted from Table IV. 


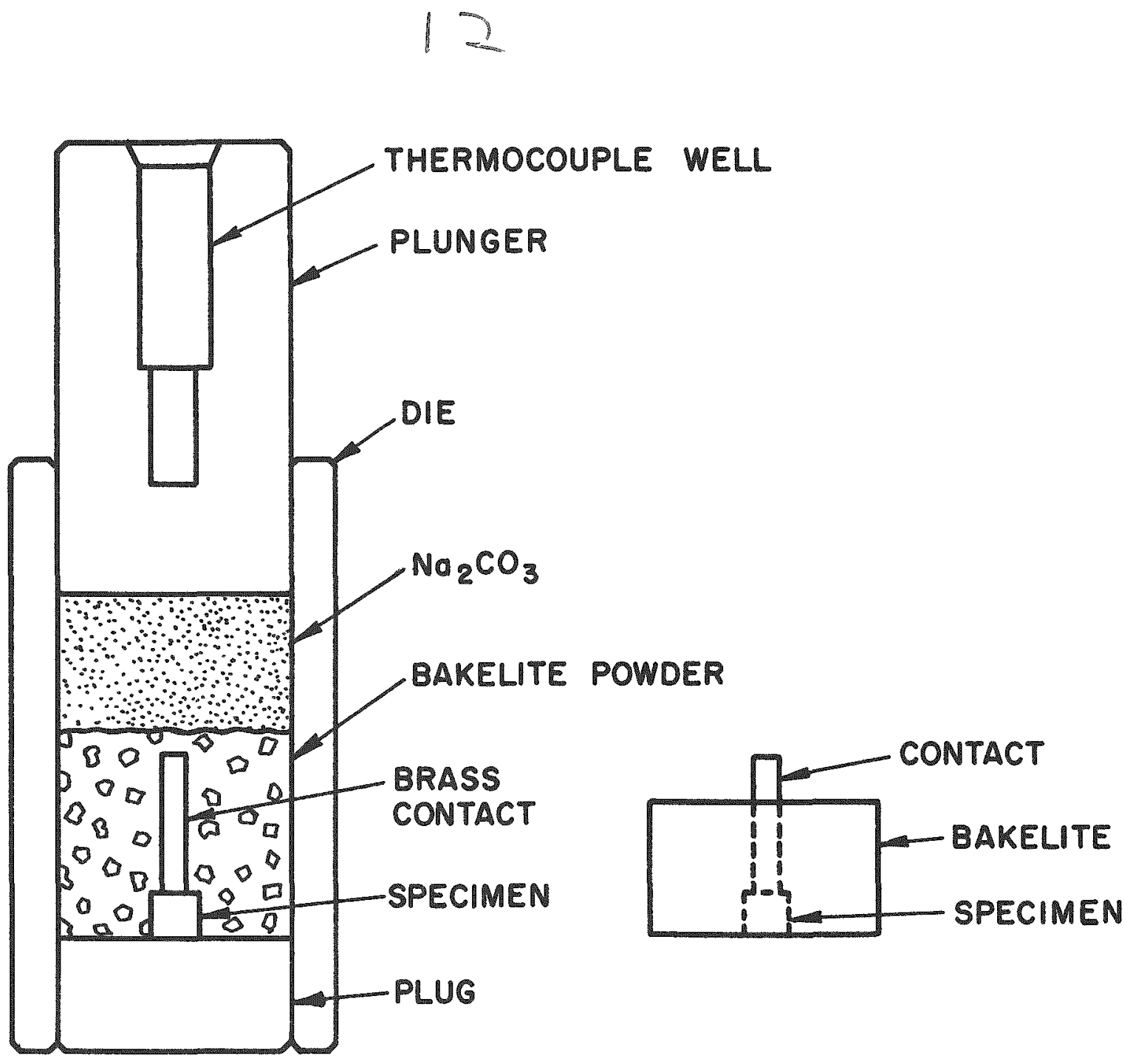

Figure 1. Procedure For Molding Electrical Contact Into Bakelite Mount.

Left: Longitudinal section through charged mold assembly ready for application of heat and pressure. After curing, the contact is exposed by breaking away the major portion of the $\mathrm{Na}_{2} \mathrm{CO}_{3}$ and then dissolving the remainder in hydrochloric acid. (NaCl may be used in place of $\mathrm{Na}_{2} \mathrm{CO}_{3}$ and the excess dissolved in water after breaking.)

Right: Finished mount, after removal of $\mathrm{Na}_{2} \mathrm{CO}_{3}$, showing protruding electrical contact. 
$1+\infty$

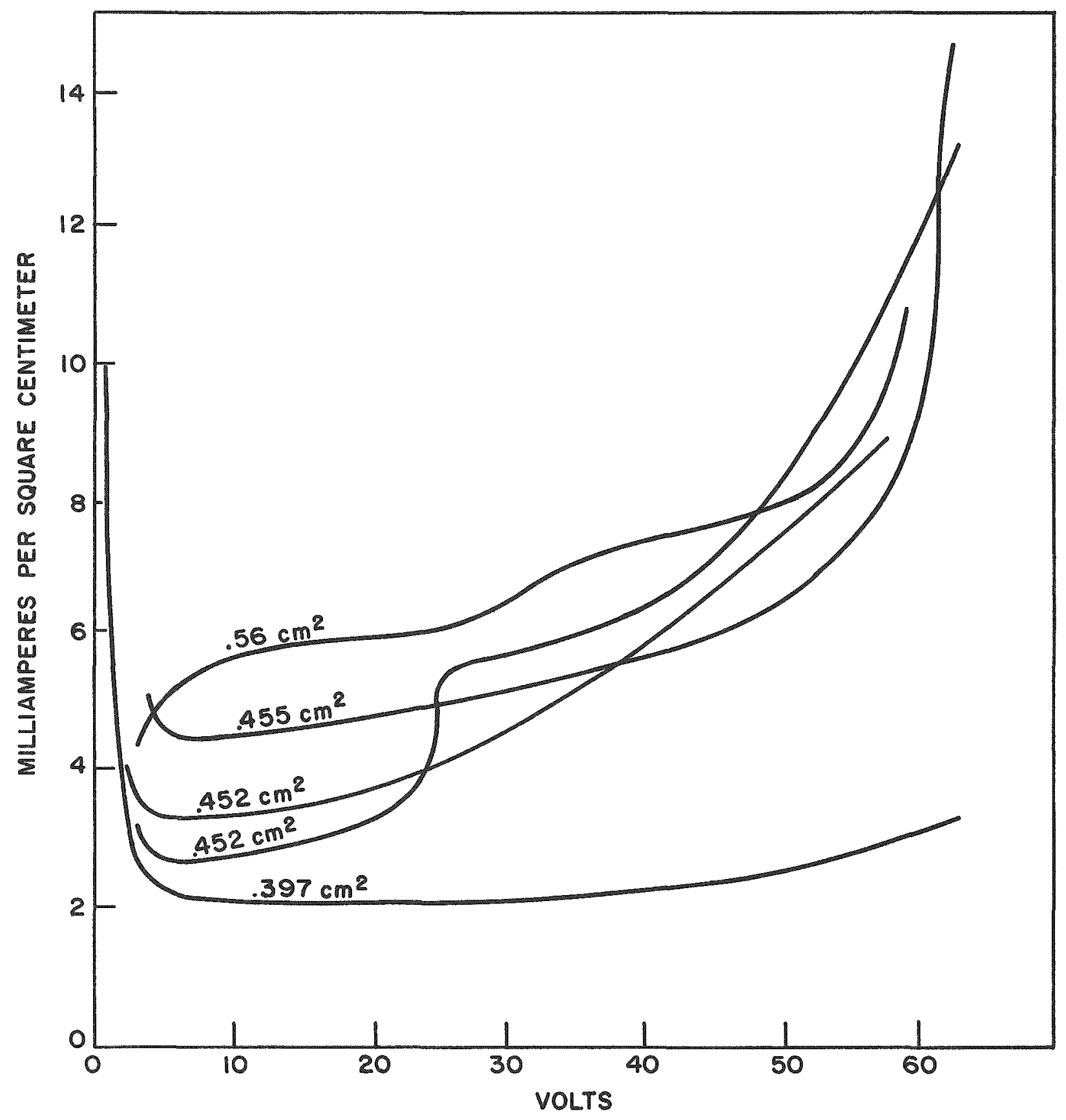

Figure 2. Electropolishing Curves for Normal Uranium

Specimens back-connected in bakelite mounts with no touch wire. Contact areas are indicated on curves. Phosphoric acid-ethylene glycol was used as electrolyte. 


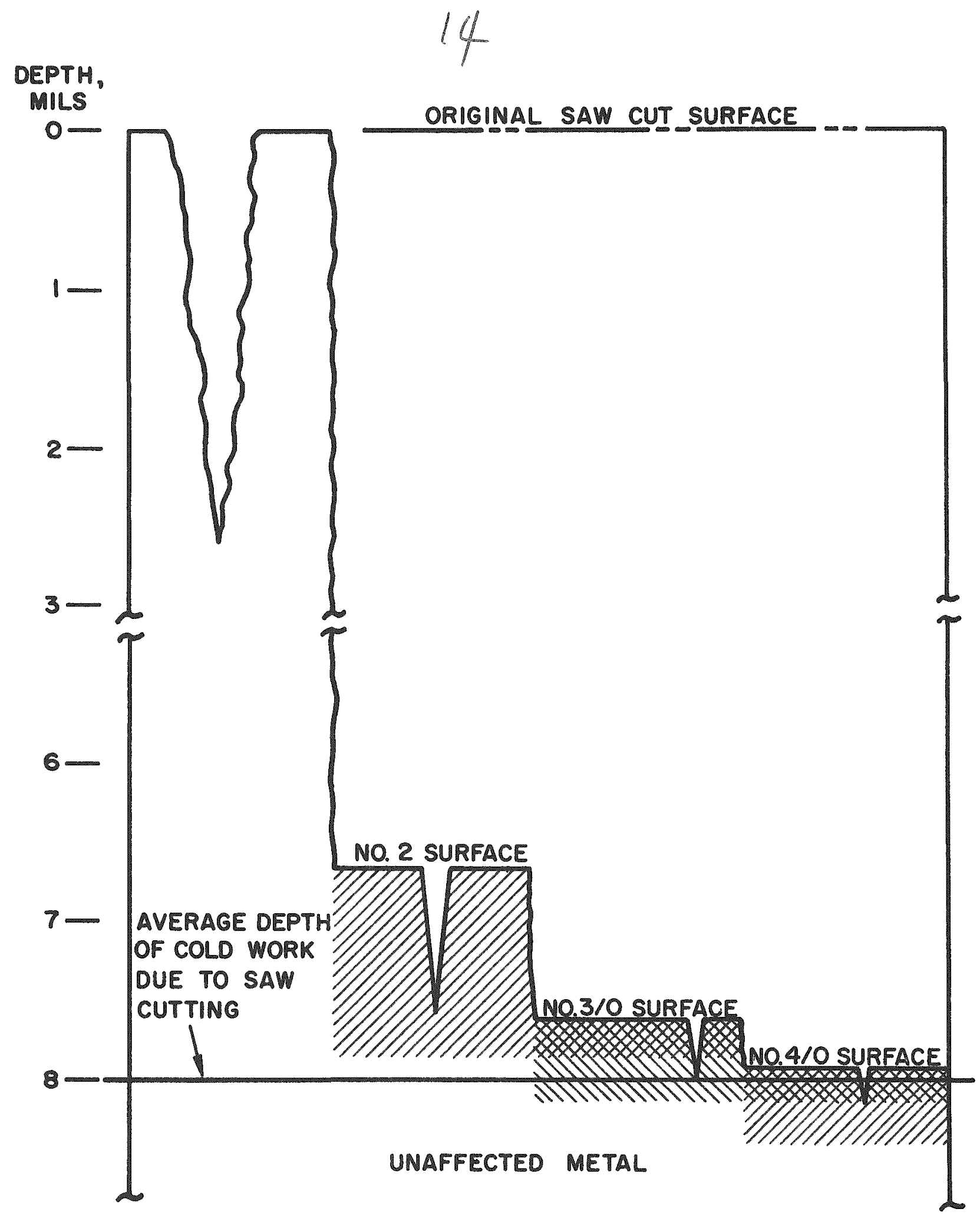

Figure 3. Depth of Scratches and Cold Worked Layers From Saw Cutting and Grinding in the Optimum Sequence of Emery Polishing Papers. 
15

Figure 4. Micros of Specimens Saw Cut and Electropolished for the Lengths of Time Indicated. All micros $100 \mathrm{x}$, polarized light illumination.

5 hre.

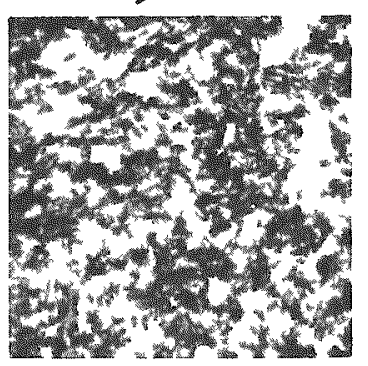

7225
$10 \mathrm{hr}$.

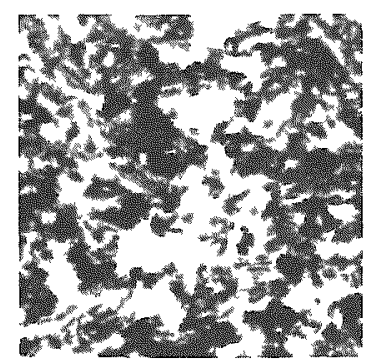

7226

$30 \mathrm{hr}$.

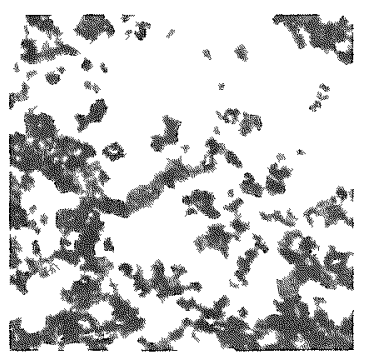

7196

$45 \mathrm{hr}$.

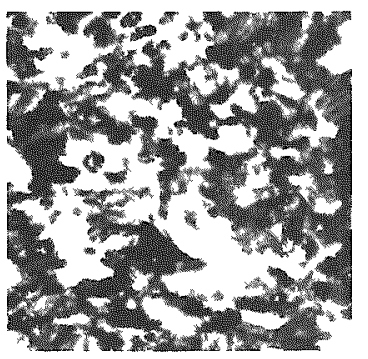

7227

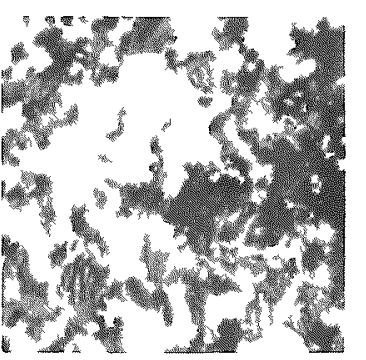

7216

$50 \mathrm{hr}$.

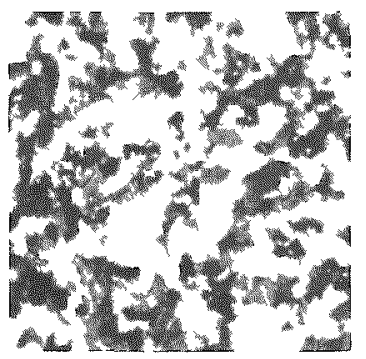

7217

$70 \mathrm{hr}$.

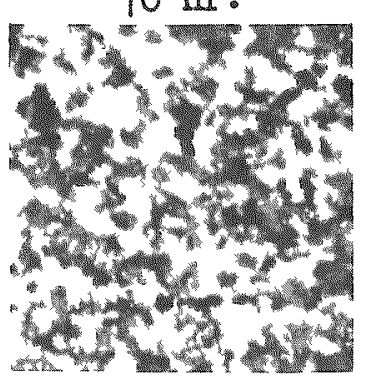

7234
$15 \mathrm{hr}$.

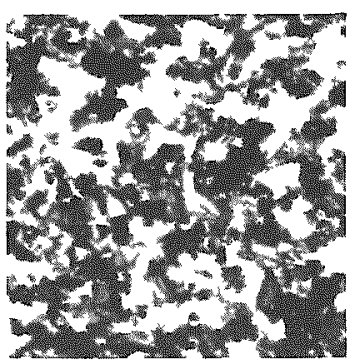

7235

$35 \mathrm{hr}$.

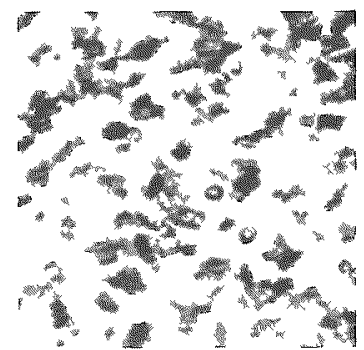

7215

$55 \mathrm{hr}$.

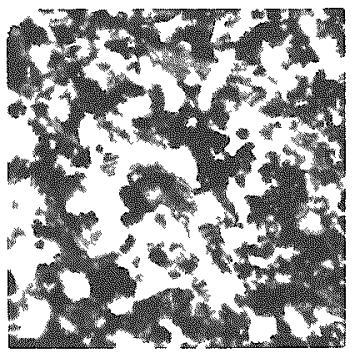

7228

$65 \mathrm{hr}$.

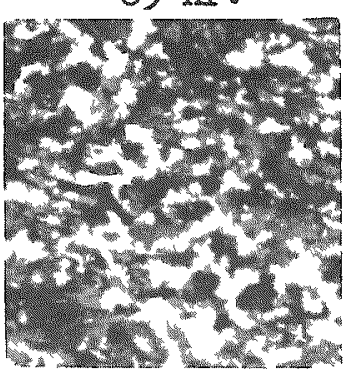

7224

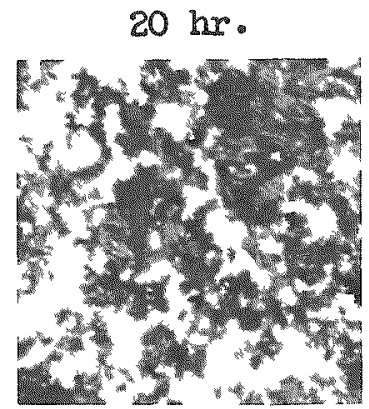

7197

$40 \mathrm{hr}$.

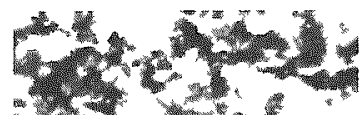
4)

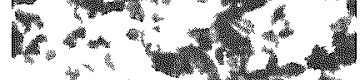

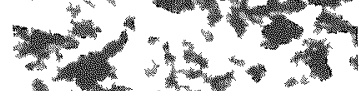

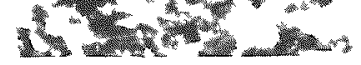

7214

$60 \mathrm{hr}$.

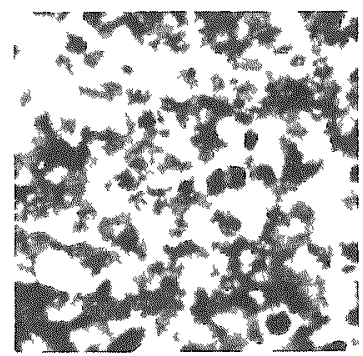

7229 
Figure 5. Micros of Specimens Saw Cut and Polished on Grade 2 Emery Polishing Paper (dry) and Electropolished for the Lengths of Time Indicated. All micros $100 \mathrm{X}$, polarized light iliumination.

$5 \mathrm{hr}$.

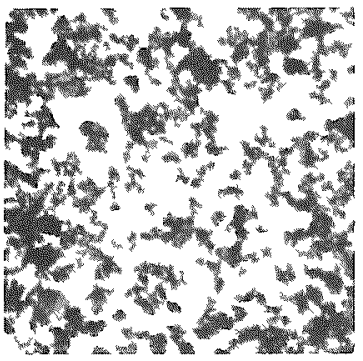

7242

$25 \mathrm{hr}$.

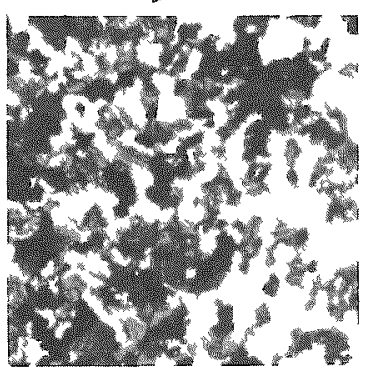

7218

$45 \mathrm{hr}$.

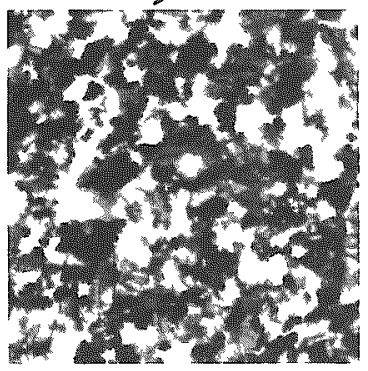

7237
$10 \mathrm{hr}$.

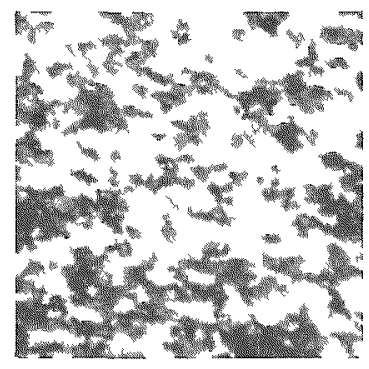

7245

$30 \mathrm{hr}$.

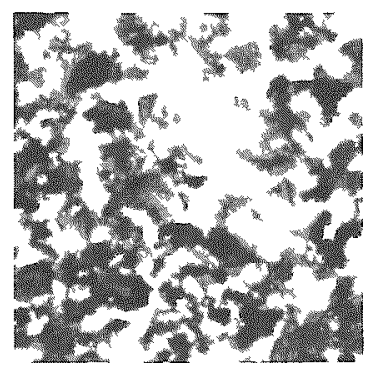

7231

$50 \mathrm{hr}$.

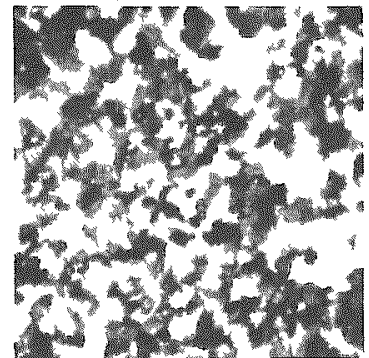

7230
$15 \mathrm{hr}$.

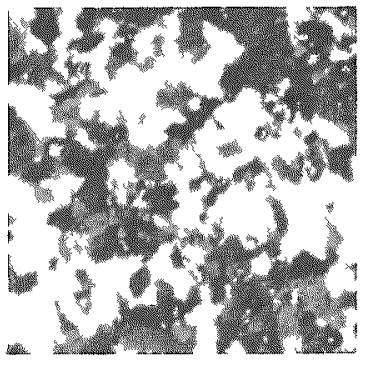

7220

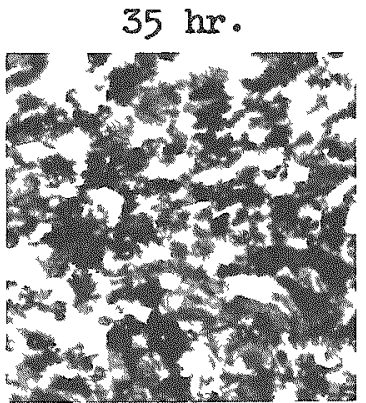

7232

$55 \mathrm{hr}$.

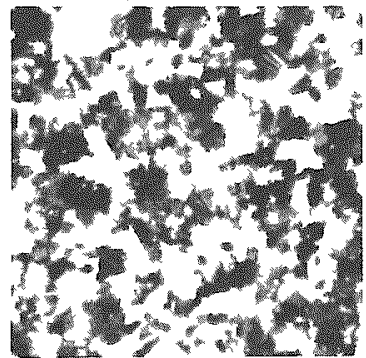

7236

$70 \mathrm{hr}$.

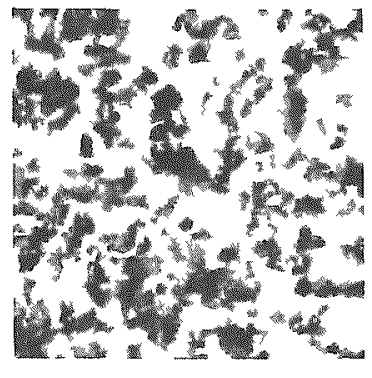

7244

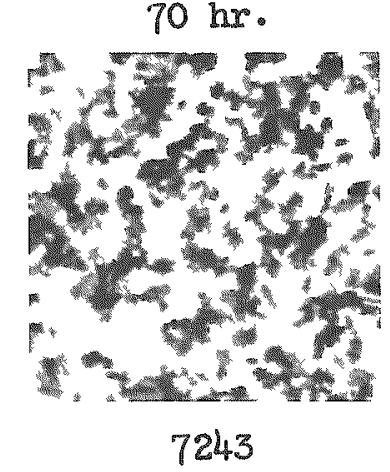

7243
$65 \mathrm{hr}$.

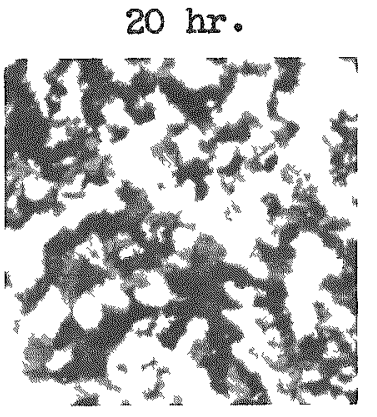

7219

$40 \mathrm{hr}$.

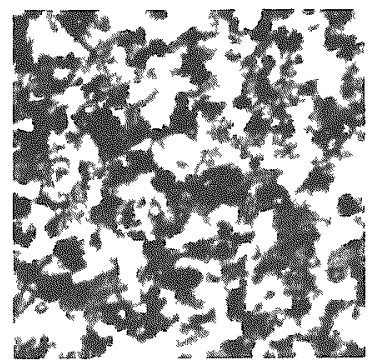

7233

$60 \mathrm{hr}$.

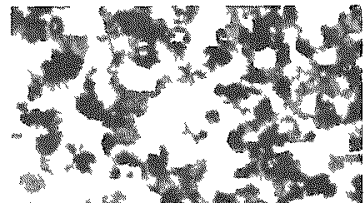

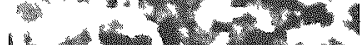

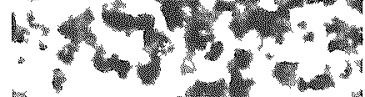
(1)

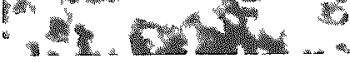

7241 
Figure 6. Micros of Specimens Saw Cut, Polished. On Grades 2 and 2/0 Brery Polishing Papers (ary) and Electropolished for the Lengths of Time Indicated. All micros $100 \mathrm{X}$, polorized light illumination.

5 hre.

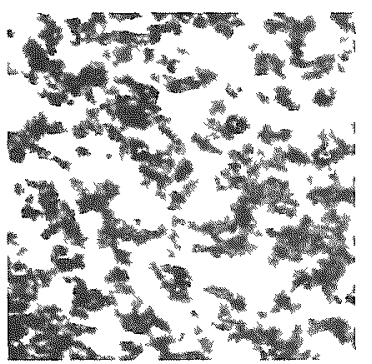

7258

$25 \mathrm{hr}$.

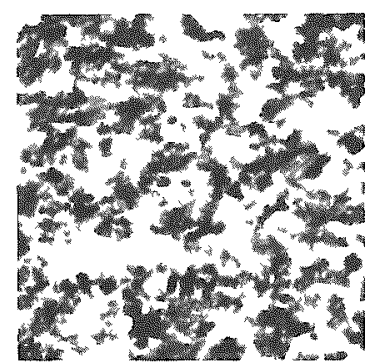

7256

$45 \mathrm{hr}$.

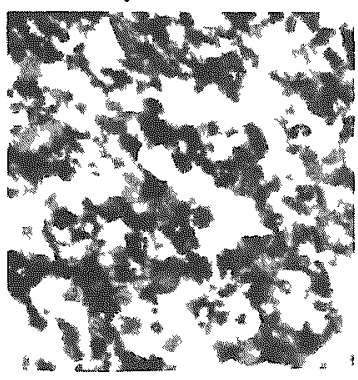

7306
$10 \mathrm{hr}$.

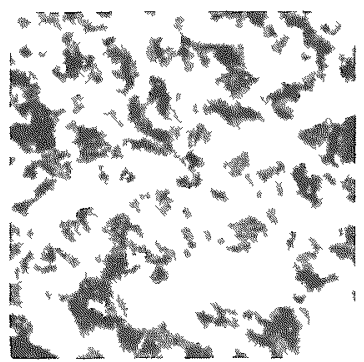

7259

$30 \mathrm{hr}$.

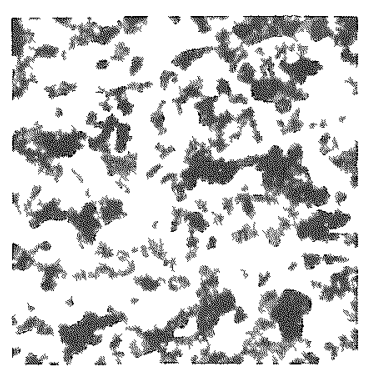

7257

$50 \mathrm{hr}$.

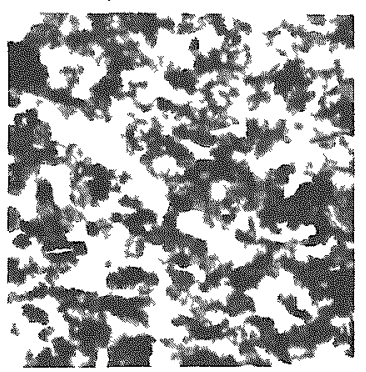

7283
$15 \mathrm{hr}$.

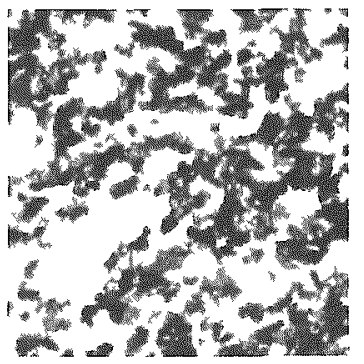

7274

$35 \mathrm{hr}$.

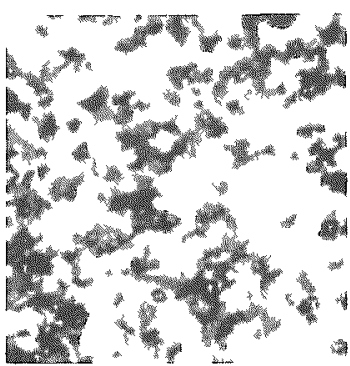

7284

$55 \mathrm{hr}$.

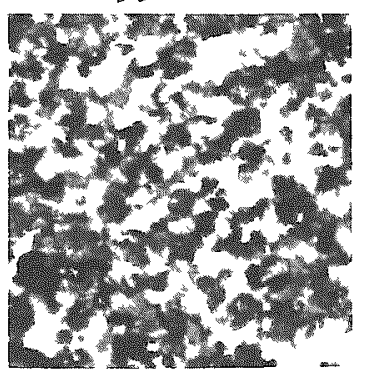

7305
$20 \mathrm{hr}$.

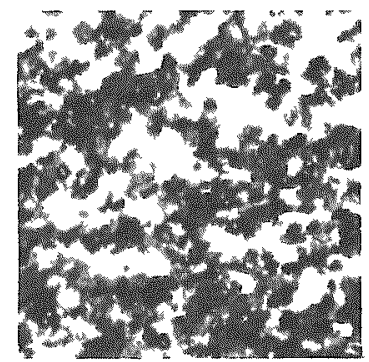

7246 $40 \mathrm{hr}$.

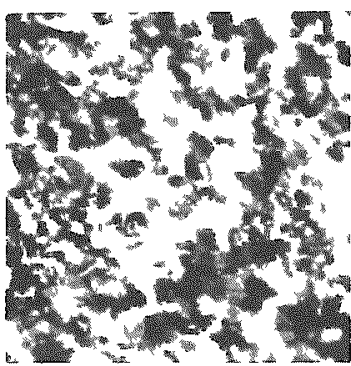

7307

$60 \mathrm{hr}$.

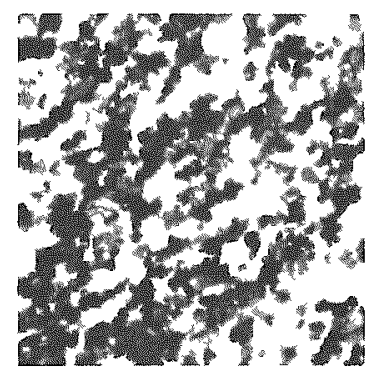

7304
$65 \mathrm{hr}$.

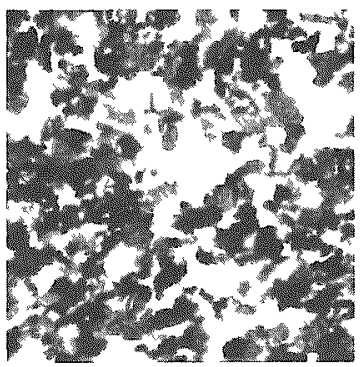

7308
$70 \mathrm{hr}$.

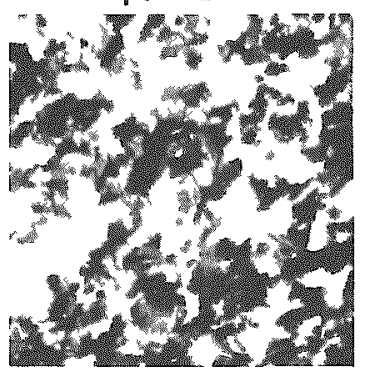

7320 
Figure 7. Micros of Specimens Saw Cut, Polished on Grades 2, 2/0 and 3/0 Emery Polishing Papers (dry) and Electropolished for the Lengths of Time Indicated. All micros $100 \mathrm{x}$, polarized light illumination.

$5 \mathrm{hr}$.

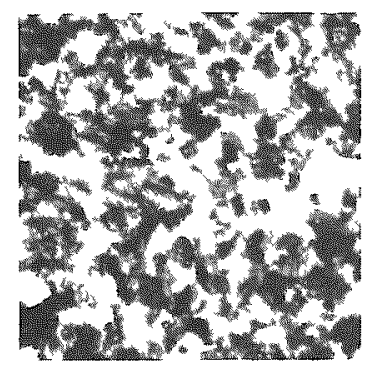

7261
$10 \mathrm{hr}$.

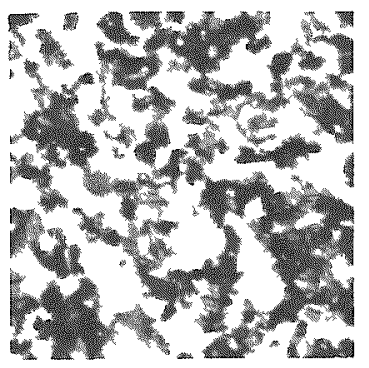

7276

$30 \mathrm{hre}$

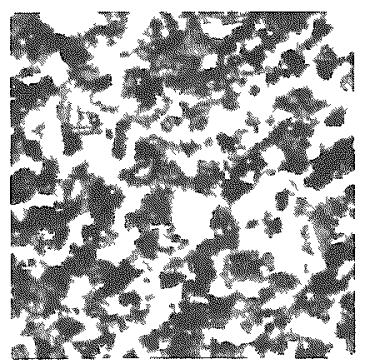

7285

$50 \mathrm{hr}$.

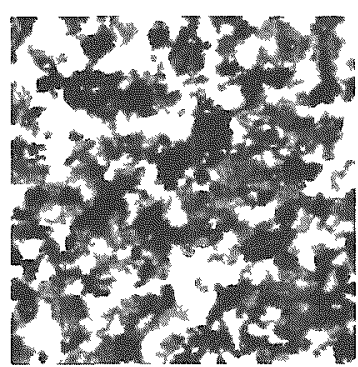

7321

$65 \mathrm{hr}$.

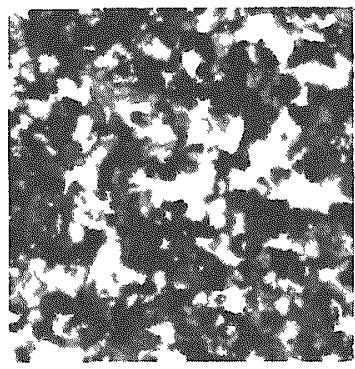

7325
$15 \mathrm{hr}$.

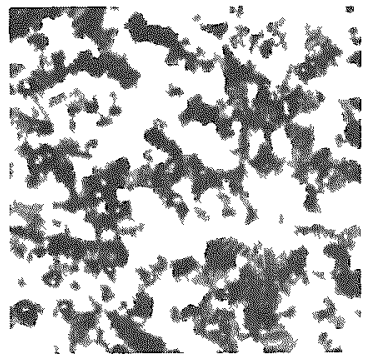

7286

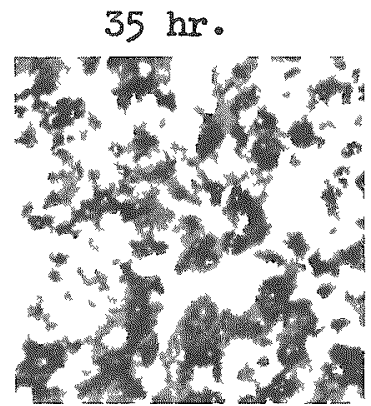

7309

55 hr.

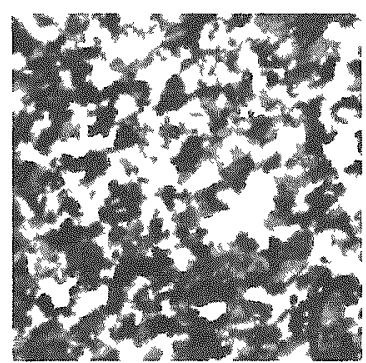

7323
$20 \mathrm{hr}$.

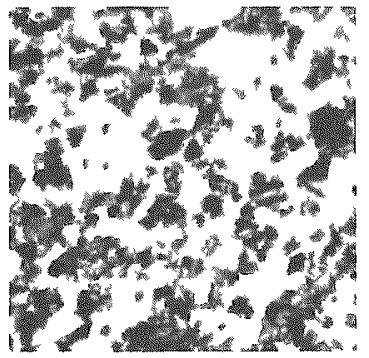

7260

$40 \mathrm{hr}$.

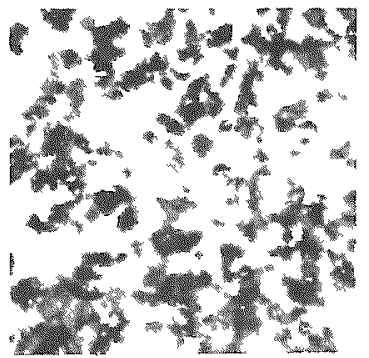

7310

$60 h r^{\circ}$.

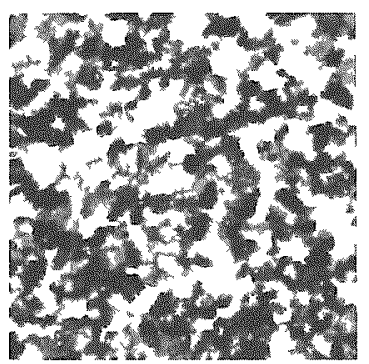

7322
$70 \mathrm{bx}$.

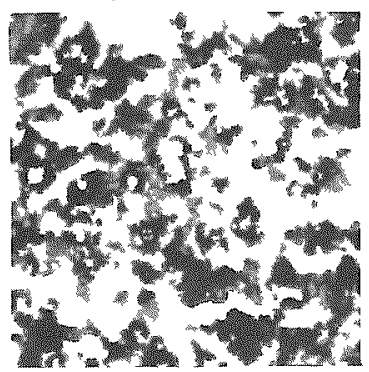

7324 


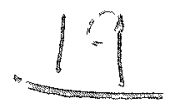

Figure 8. Micros of Specimens Saw Cut, Polished on Grades 2, 2/0, 3/0 and 4/0 Emery Polishing Papers (dry) and Electropolished for the Lengths of Time Indicated. All micros $100 \mathrm{x}$, polarized light illumination.

$5 \mathrm{hr}$.

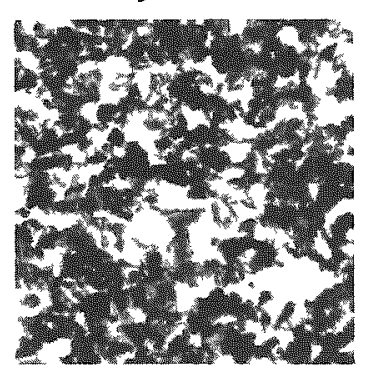

7311
$10 \mathrm{hr}$.

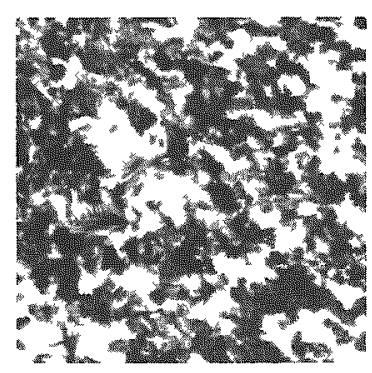

7332
$15 \mathrm{hr}$.

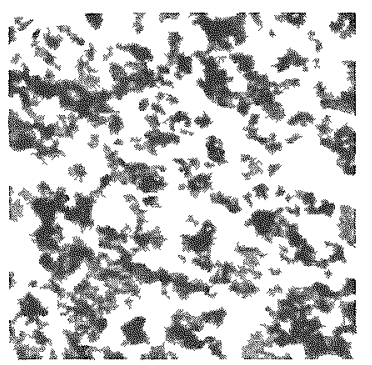

7333
$20 \mathrm{hr}$.

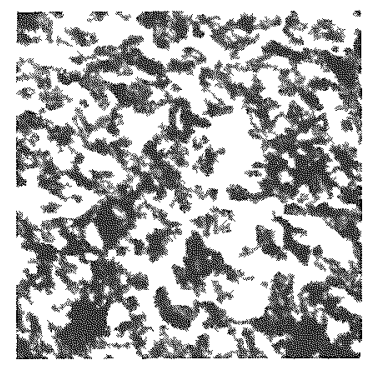

7331
$25 \mathrm{hr}$.

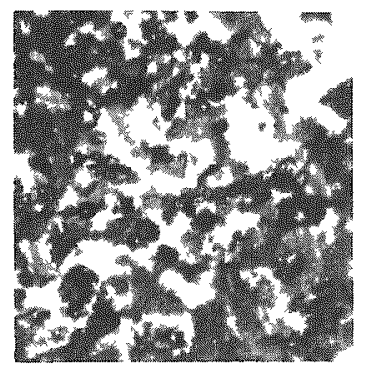

7330
$30 \mathrm{hr}$.

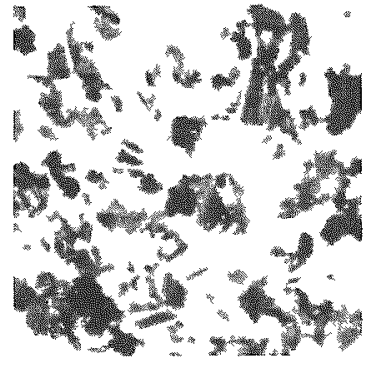

7328
$35 \mathrm{hr}$.

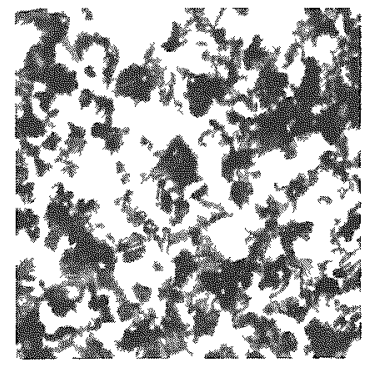

7334
$40 \mathrm{br}$.

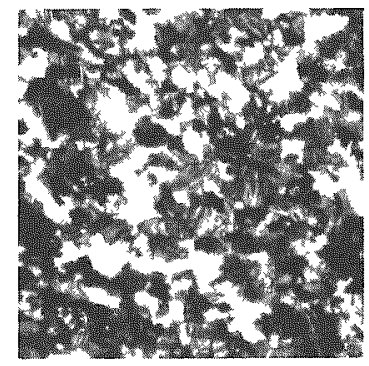

7335
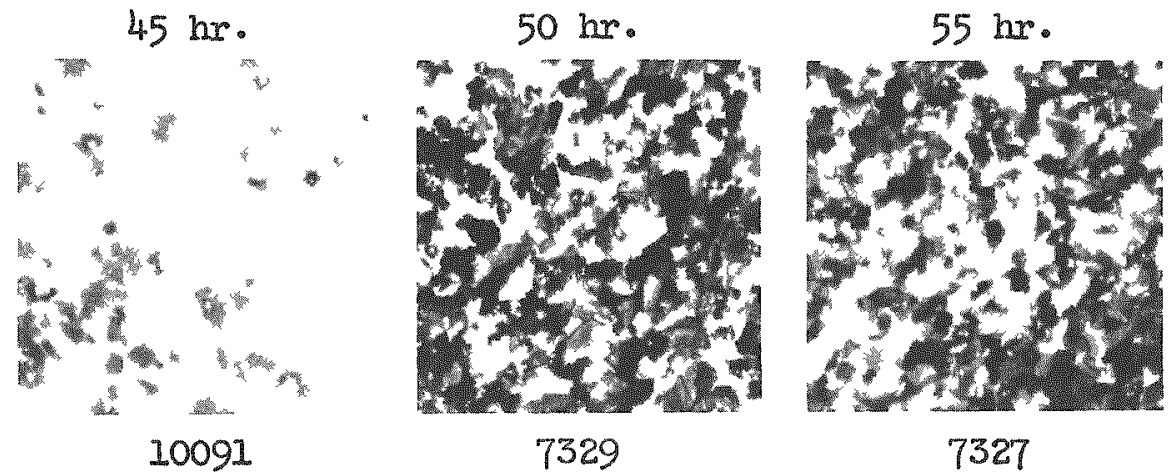